\title{
LEGAL LANGUAGE: THE PROBLEM STATEMENT
}

\author{
Roman G. Melnichenko \\ Volgograd State University, Volgograd, Russian Federation
}

\begin{abstract}
Introduction: based on the works in the field of legal technology, philology and linguistics, the paper demonstrates the social dichotomy in which, on the one hand, the importance of a special verbal form of presenting regulatory prescriptions is recognized, and on the other hand, the constant defamation, the marginalization of such a phenomenon as a "special speech of lawyers". The task is to present the arguments to the thesis about the existence of a special legal language. Methods: the methodological framework for the study is a combination of the following methods of scientific knowledge: the hermeneutical method, the method of consistency and the method of analysis. Results: the author proposes to identify a special semiotic system - legal language. Conclusions: legal language is a special communication, thought-forming and segregation system of signs. The concepts of "legal language" and "state language" are synonymous. Each developed branch of law has its own legal dialect.
\end{abstract}

Key words: language, legal language, dialect, legal dialects, state language.

Citation. Melnichenko R.G. Legal Language: The Problem Statement. Legal Concept = Pravovaya paradigma, 2021, vol. 20, no. 1, pp. 62-67. (in Russian). DOI: https://doi.org/10.15688/lc.jvolsu.2021.1.9

УДК $81: 340.113 .1$

Дата поступления статьи: 06.01.2021

ББК 81.055 .51 .3

Дата принятия статьи: 09.02.2021

\section{ЮРИДИЧЕСКИЙ ЯЗЫК: ПОСТАНОВКА ПРОБЛЕМЫ}

\author{
Роман Григорьевич Мельниченко \\ Волгоградский государственный университет, г. Волгоград, Российская Федерация
}

Введение. На основе работ в области юридической техники, филологии и лингвистики в статье демонстрируется социальная дихотомия, в которой признается, с одной стороны, важность особой словесной формы изложения нормативных предписаний, а с другой - постоянная диффамация, маргинализация такого феномена, как «особая речь юристов». В качестве задачи взято представление аргументов к тезису о наличии особого юридического языка. Методы: методологическую основу исследования составляет совокупность следующих методов научного познания: герменевтический метод, метод системности и метод анализа. Результаты: автором предлагается выделить особую семиотическую систему - юридический язык. Выводы: юридический язык - это особая коммуникационная, мыслеобразующая и сегрегационная система знаков. Понятия «юридический язык» и «государственный язык» являются синонимами. Каждой развитой отрасли права соответствует свой юридический говор.

Ключевые слова: язык, юридический язык, говор, юридические говоры, государственный язык.

Цитирование. Мельниченко Р. Г. Юридический язык: постановка проблемы // Legal Concept = Правовая парадигма. - 2021. - Т. 20, № 1. - C. 62-67. - DOI: https://doi.org/10.15688/lc.jvolsu.2021.1.9

\section{Введение}

Война за власть, как говорил Мишель Фуко, - это борьба за доминирование между дискурсами, в качестве которых выступают различные виды речей. Арена борьбы, о ко- торой пойдет речь в настоящей статье, - это государственный язык Российской Федерации. Сразу же определимся с сегодняшним победителем в этой войне - это русский литературный язык. Согласно ст. 1 Ф3 «О государственном языке Российской Федерации», 
«порядок утверждения норм современного русского литературного языка при его использовании в качестве государственного языка Российской Федерации, правил русской орфографии и пунктуации определяется Правительством Российской Федерации» [11]. Но наличие победителя еще не свидетельствует о том, что так будет оставаться всегда, или о том, что на периферии социального внимания не существует других языков, которые претендуют если не на доминирование, то хотя бы на признание.

\section{Функции языка}

Язык - это полифункциональное явление. Мы можем выделить в языке как минимум три функции: коммуникационную, мыслительную и сегрегационную.

Основная, лежащая на поверхности функция языка - коммуникационная, которая заключается в передаче информации от одного индивида другому. В контексте права это проявляется в информационной его функции. Посредством права до членов социума доводятся требования нормативных предписаний (в традиции позитивизма). Например, такой правовой институт, как промульгация, прямо свидетельствует о коммуникационной функции права, так как описывает требование и одновременно порядок доведения до сведения членов социума правовых предписаний.

Вторая функция языка - мыслеобразующая. Исследователь литературы М.М. Бахтин указывал, что «каждый момент произведения дан нам в реакции автора на него, которая объемлет собою как предмет, так и реакцию героя на него» [1, с. 9]. Идеи М.М. Бахтина дали возможность как отечественным, так и зарубежным авторам предположить, что мышление и есть интериоризованная речь. «Таким образом, в рамках концепции М.М. Бахтина о взаимодействии автора и героя произведения интериоризованный дискурс может рассматриваться как созданная автором модель внутренней речи героя. Внутренняя речь описывается и моделируется автором произведения через процесс экстериориоризации» [7, с. 106]. Здесь можно сформулировать следующий тезис: «Как мы говорим, так мы и думаем».
Опираясь на работы Р. Иеринга, который, исследуя такое явление, как «юридическая конструкция», указывал, что она, будучи особым приемом логического построения правового материала, отражает специфику юридического мышления, в юридическом дискурсе мы так же можем предположить, что юридическое мышление возможно исключительно в случае наличия такого явления, как юридическая речь, то есть юрист - это человек, говорящий на особом языке и потому имеющий особое мышление.

Третий функционал речи - сегрегащия, то есть распределение, а затем маркирование людей по социальным группам. Основной маркер отнесения человека к какой-либо страте это его речь. Является ли сообщество юристов стратой? Да, у юристов есть свой лексикон, свои глоссы, свой «язык». На эту функцию языка в контексте настоящей статьи указывают множество авторов, например Т.Д. Четвериковой: «...юристы, будучи в большинстве своем грамотными людьми, сознательно употребляют рассматриваемое слово с нарушением акцентологической нормы, дабы выявить “своего" в среде "чужих", где "свои" - юристы, а "чужие" - неюристы, и в зависимости от окружения выстроить свою речевую тактику, предполагающую, в частности, решение вопроса о том, следует ли разъяснять некоторые термины или в этом нет необходимости» $[10$, с. 88$]$. Об этом же пишет и Л.П. Крысин: «По такого рода особенностям словоупотребления профессионал легко опознает своего, собрата по профессии и, с другой стороны, безошибочно определяет речь “чужака", не владеющего профессиональными навыками использования слова» $[5$, с. 71$]$.

Налицо конфликт между двумя функциями языка: коммуникационной и сегрегационной. С одной стороны, юридические предписания должны быть понятны широкому кругу лиц, с другой - язык властных предписаний должен «обслуживаться» профессионалами, образующими особую социальную страту - юристов.

\section{Юридический язык}

Выдвинем гипотезу о наличии юридического языка как особой коммуникационной, мыслеобразующей и сегрегационной системы 


\section{ТЕОРИЯ И ПРАКТИКА ГОСУДАРСТВЕННО-ПРАВОВОГО РАЗВИТИЯ}

знаков. Для этого определимся с теми признаками, которые дают нам основание к идентификации особого юридического языка, юридической речи.

Юридический лексикон. Наличие особого юридического лексикона, который используется юристами в своей речи, не требует особых доказательств, достаточно взглянуть на начало какого-либо нормативно-правового акта, чтобы обнаружить там целый глоссарий юридических терминов. Конечно, в юридический язык включен и лексикон русского языка, что не отрицает наличие первого, как наличие иностранных слов в русском языке не отрицает наличие русского.

В свою очередь, юридический лексикон можно разделить на две части:

1) оригинальный юридический лексикон, который содержит слова, исключительно или преимущественно использующиеся в юридическом дискурсе: «сервитут», «парафирование», «пролонгация» и т. п. Вы не услышите данные слова в «обычной речи»;

2) смешанный юридический лексикон, когда в юридическом дискурсе слова или словосочетания приобретают особую строгую сему (значение), отличную от обычного значения. Например, слово «дорожка» в обычном языке понимается как маленькая дорога, а в юридическом языке - как административное или уголовное дело вследствие дорожнотранспортного происшествия. Со способами образования иных семантических значений в профессиональных дискурсах можно ознакомиться в работе М.Л. Давыдовой и Н.Ю. Филимоновой [4].

В лингвистическом дискурсе юридический лексикон относится к кластеру явлений, обозначаемых словом «профессионализмы» [8, с. 105-106]. Даже беглое исследование языкового юридического поля дает нам богатый эмпирический материал смешанного юридического лексикона, например глагол «претца» и производные «преем», «отпрелись», которые отражают такое юридическое действо, как выступать с прениями на заключительной части судебного заседания.

Неслучайно неюристы называют порой речь юристов «птичьим языком», ведь юристы говорят вроде как на русском, но на совершенно непонятном языке.
Юридическое языковое конструирование заключается в особой манере конструировать из слов более обширные языковые конструкции - словосочетания, предложения. Особо ярко такое конструирование проступает в случае сравнения этой манеры с «классической манерой построения языковых конструкций». Например, юридическая конструкция «причиняются последствия» с позиции «строгого языка» неверна, так как верно будет «наступают последствия» $[6$, c. 105-106].

Если ввести в компьютерную программу по проверке орфографии и пунктуации любой нормативно-правовой акт, то можно получить целую россыпь цветового выделения ошибок в данном тексте. При этом причиной этого будет не безграмотность законодателя, а требование особых правил юридического языка.

Юридическое закрепление юридического языка. Юридический статус языка закреплен в Конституции РФ и Ф3 «О государственном языке Российской Федерации». Согласно ст. 68 Конституции РФ, «государственным языком Российской Федерации на всей ее территории является русский язык». В соответствии со ст. 1 Закона под понятием «русский язык» понимается «современный русский литературный язык». Совершенно очевидна абсурдность данного смешения. Литературный язык - это особый общеупотребительный стиль языка, и в государственном управлении этот язык не используется. Предположим, что именно посредством юридического языка происходит государственное управление, а значит, юридический язык и является синонимом языка государственного.

Оговоримся, что в научном дискурсе такая дефиниция, как «юридический язык», пока не легализована. Максимум, что допускают специалисты в данной научной сфере, - это признание (и то не всеми) наличия юридического жаргона. Об этом в своих работах пишут, например, Н.А. Власенко [2] и В.Ю. Туранин [9].

\section{Виды отраслевых юридических говоров}

Доказательства бытия юридического языка закономерно приводят нас к необходи- 
мости дальнейшей его классификации, то есть допущения наличия в юридическом языке отдельных говоров. В данном случае под говором мы понимаем разновидность юридического языка по аналогии с говорами в лингвистике - местной разновидностью территориального, областного диалекта. Однако здесь в основание классификации мы положим не территориальный, а отраслевой признак, то есть каждой отрасли права соответствует свой юридический говор.

Лексикон говора. Наличие конституционного, уголовного, гражданско-правового и иных юридических говоров легко обосновать наличием особенного для каждой отрасли лексикона. Ведь каждый нормативно-правовой акт отрасли является толковым словарем именно этого юридического говора. Мы можем найти очень развернутые определения таких слов, как «Государственная дума», «кража», «сделка» и т. п. Помимо слов, закрепленных законодательно, существуют слова юридических говоров, функционирующие в устной речи, например «кассашка» - кассационная жалоба, «засилить» - оставить приговор в силе в апелляционной или кассационной инстанции и т. п.

О наличии юридических говоров говорит и тот факт, что одно и то же слово в различных юридических говорах имеет различное семантическое значение. Например, согласно ст. 5 Уголовно-процессуального кодекса РФ под понятием «близкие родственники» понимаются: супруг, супруга, родители, дети, усыновители, усыновленные, родные братья и родные сестры, дедушка, бабушка, внуки, а согласно ст. 14 Семейного кодекса, «близкие родственники» - это родственники по прямой восходящей и нисходящей линиям (родители и дети, дедушка, бабушка и внуки), полнородные и неполнородные (имеющие общих отца или мать) братья и сестры. То есть в уголовно-процессуальном юридическом говоре супруг - это близкий родственник, а в семейном - нет.

Говор юридических говоров - это особая манера произношения в отдельных юридических говорах. Помимо отличий в лексиконе, юридические говоры отличаются и произношением. Некоторые исследователи идентифицируют говор как обыкновенную ошибку, вводя антиномию «литературный язык» и «сниженная лексика»: например, рассматривают произношение слова «осУжденный» как «просто типичную для профессионального юридического языка ошибку» [3, с. 211]. Однако мы не были бы так категоричны, относя юридические говоры к ошибкам, так как видим в них огромный функциональный потенциал. Определимся с признаками говора в понимании манеры произношения в отдельных юридических стратах.

Форма существования говора - это устная речь, в отличие от юридического лексикона, который преимущественно закрепляется в формально-определенной знаковой системе. Конечно, мы можем обозначить говор и в письменной речи, для этого служат интонационные знаки, но это высушенный, безжизненный говор.

Место жительство говора - это коммуникационные площадки. Лингвисты до сих пор определяют локацию говора буквально физическим местом: край, город, хутор. Но это уже далеко не точно. Место может быть и виртуальным. То есть это сфера общения, где происходят разговоры на определенные, в нашем случае профессиональные темы: чат в сети Интернет, место для курения около здания суда и т. п.

Интонационное конструирование говора. Говор идентифицируется интонационно. Интонация - довольно сложное явление, сложенное из следующих параметров:

- темп (быстро - медленно);

- тон (высоко - низко);

- громкость (тихо - громко).

Как правило, говор идентифицируется посредством ударения, которое русскоязычными слышится как модулирование экспираторного элемента (громкость) и квантитативного (замедление). Например, в слове «осУжденный» представители юридического говора букву «у» произносят более громко (экспираторно) и более продолжительно (квантитативно).

Один единственный юридический говор. Учитывая вышеизложенное, в юридической среде мы можем идентифицировать наличие говора лишь в одном сегменте. Представители этой страты связаны с уголовнопроцессуальным правом. Существует три слова этого уголовно-юридического говора: «возбУждено», «осУждено», «Эксперт». Почему 


\section{ТЕОРИЯ И ПРАКТИКА ГОСУДАРСТВЕННО-ПРАВОВОГО РАЗВИТИЯ}

так происходит? Эти люди своим говором отмечают, что у них есть своя социальная страта. Они специально, умышленно нарушают правила русского языка.

Полевые испытания по идентификации юридического говора.

В рамках научного исследования нами были проведены полевые испытания, условия которых были следующие:

- субъекты - адвокаты, специализирующиеся на ведении уголовных дел;

- локация - коммуникационный профессиональные площадки в социальных сетях «Повышение квалификации адвокатов».

В Сети был размещен блог следующего содержания: «Уважаемые адвокаты! Где вы ставите ударение в словах: “возбуждено", “осужден” и “эксперт”? Ваши комментарии очень помогут нам в исследовании юридических говоров».

В основном адвокаты транслировали словарное ударение, указывая, что только так говорят приличные люди: «С точки зрения акцентологической нормы русского языка? Орфоэпический словарь никто пока не отменил, зачем это обсуждать?»

В ходе обсуждения были зафиксированы и другие слова юридического говора: «прИговор», «Исковое заявление», «ходатАйство», «ходательство».

Были обнаружены рефлексия такого явления, как юридический говор, и использование этих знаний, например, в качестве развлечения: «Я над судьями издеваюсь. Пишу в документах “осуждённый», “возбуждённое дело». Когда они оглашают эти документы, часто сбиваются)))».

Были выявлены рефлексивные подстройки под юридический говор: «Когда перешла на уголовные дела из гражданских сначала говорила с ударением на последний слог. Но все вокруг: прокурор, следователи и судьи говорили осУжден, возбУждено. Теперь я как хамелеон - тоже говорю осУжден. Иначе всем остальным в процессе режет ухо». К подобным наблюдения можно отнести и следующее: «Когда работал в милиции говорил возбу́ждено, э'ксперт, а сейчас говорю как все))))» или «ВозбужденО, осуждЁн, экспЕрт. Думаю, меня не затронуло неправильно произношение, потому что я не так долго работаю».
Рефлексируя несловарное ударение, честь юристов относят это к такому явлению, как профессиональная деформация: «ВозбУждено, осУжден, экспЕрт. Я знаю,что первые два слова неверны,но, простите, профдеформация».

Были выделены не только внутрикорпоративные, но и поколенческие аспекты, проявляющиеся в говоре: «Забавно звучит употребление этих слов именно у “старшего" поколения “специалистов”. Моя бабушка адвокат и она именно так говорит, как я написала выше. Ей 83) из них 30 лет следователь по особо важным. Этот “Диалект” уже не “выбить"))) да и вреда от него нет))».

Интересно наблюдение по поводу наличия говора в других славянских языках: «ВозбужденО, осуждЕн, экспЕрт. Но в Беларуси среди коллег более распространены возбУждено, осУжден, Эксперт».

Некоторые респонденты говорили и о функционале юридического говора: «У одной коллеги был перл: "Не вижу обходимости". $<$...> А вообще это сигнальная система определенного менталитета: "ВозбУждено" свои! Проходи! Если что, слэнгом никогда не пользовалась и в “свои” не стремилась».

\section{Результаты}

Описан такой феномен, как «юридический язык», представлен конфликт между русским литературным языком и юридическим русским языком на уровне функционала. Обосновано существование в рамках юридического языка особых юридических говоров.

\section{Заключение}

Юридический язык - это особая коммуникационная, мыслеобразующая и сегрегационная система знаков. Понятия «юридический язык» и «государственный язык» являются синонимами. Каждой развитой отрасли права соответствует свой юридический говор.

\section{СПИСОК ЛИТЕРАТУРЫ}

1. Бахтин, М. М. Эстетика словесного творчества / М. М. Бахтин. - М. : Искусство, 1986.

2. Власенко, Н. А. Жаргоны в праве: пределы и техника использования / Н. А. Власенко // Про- 
блемы юридической техники / под ред. В. М. Баранова. - Н. Новгород : [б. и.], 2000. - С. 264-270.

3. Давыдова, М. Л. Место юридических конструкций в системе технико-юридических средств / М. Л. Давыдова // Юридическая техника. - 2013. № 7-2.

4. Давыдова, М. Л. Профессиональный юридический жаргон: проблема определения границ понятия / М. Л. Давыдова, Н. Ю. Филимонова // Юрислингвистика. - 2013. - № 2 (13). - С. 16-23.

5. Крысин, Л. П. Часть І. Социальная дифференциация системы современного русского языка / Л. П. Крысин // Современный русский язык. Социальная и функциональная дифференциация / отв. ред. Л. П. Крысин. - М. : Яз. слав. культуры, 2003. C. 33-100.

6. Недоступова, Л. В. Современный диалект как форма коммуникации / Л. В. Недоступова // Актуальные вопросы современной филологии и журналистики. - 2016. - № 2 (21).

7. Погребняк, Ю. В. Взаимодействие автора и персонажа в интериоризованном дискурсе / Ю. В. Погребняк // Вестник ИГЛУ. - 2011. -№ 1 (13).

8. Сердобинцева, Е. Н. Проблема профессионализмов в современной лексикографии / Е. Н. Сердобинцева // Известия ВУЗов. Поволжский регион. Гуманитарные науки. - 2008. - № 4.

9. Туранин, В. Ю. Юридический жаргон: понятие, примеры, оценка / В. Ю. Туранин // Юрислингвистика-11 : Право как дискурс, текст и слово : межвуз. сб. науч. тр. / под ред. Н. Д. Голева, К. И. Бринева. Кемерово: [б. и.], 2011.

10. Четверикова, Т. Д. «Тело возбуждено́, а дело возбу́ждено»? / Т. Д. Четверикова // Русская речь. 2020. - № 6 .

11. Федеральный закон от 01.06.2005 № 53-Ф3 «О государственном языке Российской Федерации» // Собрание законодательства РФ. - 2005. - 6 июня (№ 23). - Ст. 2199.

\section{REFERENCES}

1. Bahtin M.M. Aesthetics of verbal creativity. Moscow, Art, 1986.

2. Vlasenko N.A. Jargons in Law: Limits and Technique of Use. Baranov V.M., ed. Legal technology problems. N. Novgorod, 2000, pp. 264-270.

3. Davydova M.L. The place of legal structures in the system of technical legal means. Legal technique, 2013, no. 7-2.

4. Davydova M.L., Filimonova N.Yu. Professional legal jargon: the problem of defining the boundaries of a concept. Legal linguistics, 2013, no. 2 (13), pp. 16-23.

5. Krysin L.P. Chast' I. Social differentiation of the system of the modern Russian language. Krysin L.P., ed. Modern Russian language. Social and functional differentiation. Moscow, Yazyki slavyanskoj kul'tury Publ., 2003, pp. 33-100.

6. Nedostupova L.V. Modern dialect as a form of communication. Actual problems of modern philology and journalism, 2016, no. 2 (21).

7. Pogrebnyak Yu.V. Interaction between author and character in internalized discourse. Bulletin IGLU, 2011, no. 1 (13).

8. Serdobinceva E.N. The problem of professionalism in modern lexicography. Izvestiya VUZov. Volga region. Humanitarian sciences, 2008, no. 4.

9. Turanin V.Yu. Legal jargon: concept, examples, assessment. Golev N.D., Brinev K.I., ed. Jurislingvistika-11: Law as discourse, text and word: Interuniversity collection of scientific papers. Kemerovo, 2011.

10. Cetverikova T.D. "The body is agitated, but the case is agitated"? Russian speech, 2020, no. 6 .

11. Federal Law of June 1, 2005 no. 53-FZ "On the State Language of the Russian Federation". Collected Legislation of the Russian Federation, 2005, June 6 (no. 23), Art. 2199.

\section{Information About the Author}

Roman G. Melnichenko, Candidate of Sciences (Jurisprudence), Associate Professor, Leading Researcher, Institute of Law, Volgograd State University, Prosp. Universitetsky, 100, 400062 Volgograd, Russian Federation, romanmelnichenko@yandex.ru, melnichenko@volsu.ru, https://orcid.org/0000-0003-2496-1511

\section{Информация об авторе}

Роман Григорьевич Мельниченко, кандидат юридических наук, доцент, ведущий научный сотрудник института права, Волгоградский государственный университет, просп. Университетский, 100, 400062 г. Волгоград, Российская Федерация, romanmelnichenko@yandex.ru, melnichenko@volsu.ru,https://orcid.org/0000-0003-2496-1511 